\title{
Microbial Communities of Lycaenid Butterflies Do Not Correlate with Larval Diet
}

\author{
Melissa R. L. Whitaker ${ }^{1,2 *}$, Shayla Salzman ${ }^{1}$, Jon Sanders ${ }^{3}$, Martin Kaltenpoth ${ }^{2,4}$ and \\ Naomi E. Pierce ${ }^{1 *}$ \\ 'Department of Organismic and Evolutionary Biology, Museum of Comparative Zoology, Harvard University, Cambridge, MA, \\ USA, ${ }^{2}$ Insect Symbiosis Research Group, Max Planck Institute for Chemical Ecology, Jena, Germany, ${ }^{3}$ Department of \\ Pediatrics, University of California San Diego, La Jolla, CA, USA, ${ }^{4}$ Department for Evolutionary Ecology, Johannes \\ Gutenberg University, Mainz, Germany
}

Herbivores possess many counteradaptations to plant defenses, and a growing body of research describes the role of symbiotic gut bacteria in mediating herbivorous diets among insects. However, persistent bacterial symbioses have not been found in Lepidoptera, despite the fact that perhaps 99\% of the species in this order are herbivorous. We surveyed bacterial communities in the guts of larvae from 31 species of lycaenid butterflies whose caterpillars had diets ranging from obligate carnivory to strict herbivory. Contrary to our expectations, we found that the bacterial communities

Edited by:

Thomas Carl Bosch, University of Kiel, Germany

Reviewed by: Irene Lucile Garcia Newton, Indiana University Bloomington, USA Nichole A. Broderick University of Connecticut, USA

${ }^{*}$ Correspondence:

Melissa R. L. Whitaker melliwhitaker@gmail.com Naomi E. Pierce

npierce@oeb.harvard.edu

Specialty section

This article was submitted to Microbial Symbioses, a section of the journal

Frontiers in Microbiology

Received: 19 September 2016 Accepted: 15 November 2016 Published: 30 November 2016

Citation:

Whitaker MRL, Salzman S,

Sanders J, Kaltenpoth M and

Pierce NE (2016) Microbial Communities of Lycaenid Butterflies Do Not Correlate with Larval Diet.

Front. Microbiol. 7:1920. doi: 10.3389/fmicb.2016.01920 of carnivorous and herbivorous caterpillars do not differ in richness, diversity, or composition. Many of the observed bacterial genera are commonly found in soil and plant surfaces, and we detected known homopteran endosymbionts in the guts of homopterophagous species, suggesting that larvae acquire gut bacteria from their food and environment. These results indicate that lycaenid butterflies do not rely on specific bacterial symbioses to mediate their diverse diets, and provide further evidence of taxonomically depauperate bacterial communities among Lepidoptera.

Keywords: Lycaenidae, Lepidoptera, gut microbiome, horizontal gene transfer, herbivory, aphytophagy

\section{INTRODUCTION}

Plants present numerous nutritional and defensive challenges to potential herbivores, and a large and growing body of research emphasizes the role of symbiotic microbes in ameliorating herbivorous diets. The argument that symbiotic bacteria can facilitate herbivory among insects is not new (Berenbaum, 1988; Barbosa et al., 1991; Felton and Tumlinson, 2008; Feldhaar, 2011), but with advances in high-throughput sequencing technologies, it has become increasingly feasible to describe the bacterial communities associated with insects and identify the contributions that symbiotic bacteria make to host nutrition.

Bacterial genomes encode vastly more diverse metabolic capabilities than eukaryotic genomes (Lapierre and Gogarten, 2009), such that symbiotic gut bacteria can profoundly expand the metabolic repertoire of their insect hosts. For example, bacteria can help insects to degrade indigestible plant fibers: bacterially mediated cellulose degradation has been shown in beetles (Bayon and Mathelin, 1980; Vazques-Arista et al., 1997), and the guts of bees are known to harbor bacteria that aid in the degradation of pectin found in pollen (Engel et al., 2012). Some bacteria are capable of detoxifying plant secondary compounds such as phenolics, glucosinolates, and some 
alkaloids (Hammer and Bowers, 2015), thereby enabling their insect hosts to feed on chemically defended plants (e.g., Boone et al., 2013). Other bacteria are capable of synthesizing essential amino acids (Baumann, 2005) and vitamins that are unavailable from plant tissues and which insects are incapable of synthesizing on their own (Salem et al., 2014). One of the most striking examples of insect-bacterial nutritional symbiosis is the wellknown association between aphids and their endosymbiont Buchnera (Douglas, 1998), with similar obligate associations in other sap-feeding Hemiptera. Given that bacterial symbionts can so profoundly influence the diets of their insect hosts, it is not surprising that many nutritional partnerships between herbivorous insects and their gut bacteria have led to host plant specialization and expansion (Tsuchida et al., 2004; Janson et al., 2008; Sudakaran et al., 2015). The gut microbiomes of diverse groups of insects are now recognized as key factors in shaping and promoting ecological diversification (Hammer and Bowers, 2015).

Persistent bacterial associations are known in several major insect orders, including the Coleoptera (Campbell et al., 1992; Scott et al., 2008; Ceja-Navarro et al., 2015), Hemiptera (Buchner, 1965; Douglas, 1998; McCutcheon and von Dohlen, 2011; Salem et al., 2012), Hymenoptera (Kaltenpoth et al., 2005; Russell et al., 2009b; Martinson et al., 2011; Sanders et al., 2014), Diptera (Behar et al., 2005; Shin et al., 2011; Wang et al., 2013), and Blattodea (Potrikus and Breznak, 1981; Brune, 2014; Hongoh, 2014). However, they have yet to be described in detail for Lepidoptera. The Lepidoptera form one of the largest insect orders and include many economically important species that act as agricultural pests, conservation targets, pollinators, and biological models. They are also a largely herbivorous group, with the overwhelming majority of species feeding on plants (Strong et al., 1984).

The prevalence of herbivorous diets makes Lepidoptera good candidates for investigating potential bacterial contributions to mediating the challenges of herbivory. Studies of lepidopteran gut microbiomes have focused largely on pest species and laboratory models (e.g., Broderick et al., 2004; Brinkmann et al., 2008; Robinson et al., 2010; Belda et al., 2011; Tang et al., 2012). These studies have found relatively simple, often transient bacterial communities, suggesting that specialized bacterial associations may not be as important for Lepidoptera as they are in other insect groups. However, most of these studies focus on a single species reared under laboratory conditions, often on artificial media (but see Hammer et al., 2014; Staudacher et al., 2016). While other studies have looked at bacterial shifts in response to different host plant use (Priya et al., 2012; Tang et al., 2012; Landry et al., 2015) or in inducing host plant shifts (Tsuchida et al., 2004), none have explored the role of bacterial communities in mediating major dietary transitions within the group.

We conducted a comparative study of the gut microbiomes of carnivorous and herbivorous Lepidoptera to provide context to the role of the microbiome in facilitating major transitions to and from herbivorous diets. Aphytophagy has arisen multiple times within the Lepidoptera: it is known from at least 14 families of moths, and in particular, has arisen many times within the butterfly family Lycaenidae, most likely as a result of the close associations between lycaenid larvae and ants (Pierce, 1995). The diversity of feeding ecologies makes the Lycaenidae an ideal system to look into a potential microbial association with diet in the Lepidoptera.

Most lycaenid species associate with ants during their larval stages. Caterpillars produce nutritious secretions from specialized exocrine glands to reward and appease ants in exchange for ants' protective services. Ant-lycaenid interactions are diverse, and although the majority of these associations are considered mutualistic, a number of species have switched to parasitic lifestyles in which caterpillars enter their host ants' nests and feed either on ant regurgitations (trophallaxis) or directly on ant brood. Other species indirectly parasitize their host ants by feeding on ant-tended insects such as aphids, mealybugs, and planthoppers (Fiedler, 1991; Pierce et al., 2002). Thus lycaenid diets range from phytophagy on specialized host plants to strict aphytophagy on ants and ant-associated insects. Whereas lycaenids comprise a relatively small number of lepidopteran species, they represent a disproportionate number of carnivorous Lepidoptera (Pierce, 1995), and herbivorous and carnivorous species are dispersed across the group, with at least 13 independent origins of carnivory within otherwise herbivorous clades (Pierce et al., 2002).

Given the unusual diversity of feeding ecologies among lycaenids, it follows that larvae with different diets might require different assemblages of bacteria in their guts to modulate their extreme diets. Herbivorous species may harbor bacteria that assist with degrading plant cell walls, detoxifying plant allelochemicals, or provisioning nitrogen or other nutrients that are unavailable from their host plants. Conversely, maintaining associations with these same gut microbes would not be beneficial for carnivorous species that experience a different suite of dietary challenges. Instead, carnivorous species may require a gut community that is effective in fatty acid or protein metabolism, or degrading the chitinous exoskeletons of their insect prey.

Earlier surveys of the heritable bacteria associated with adult lycaenid butterflies and ants (Russell et al., 2009a, 2012) found that lycaenids harbor only two vertically transmitted symbionts, Wolbachia and Spiroplasma - and Wolbachia was by far the most dominant heritable symbiont found in association with the species surveyed. Wolbachia are known reproductive manipulators in many Lepidoptera (Hurst et al., 1999; Jiggins et al., 2000; Hiroki et al., 2002), though recent work has shown that Wolbachia can provide a defensive advantage in some insects (Hedges et al., 2008; Hamilton and Perlman, 2013; Becerra et al., 2015), and even act as a nutritional mutualist in others (Brownlie et al., 2009; Hosokawa et al., 2010; Nikoh et al., 2014), raising the possibility that Wolbachia may be important symbionts in lycaenid larvae as well.

In this study, we investigated the gut bacterial communities associated with wild-caught carnivorous Lycaenidae and their herbivorous relatives. We sampled broadly across the Lycaenidae 
to identify potential convergence in the bacterial communities associated with species with similar larval diets.

\section{MATERIALS AND METHODS}

\section{Sample Collection}

Samples were collected in 2014 and 2015 in the United States, Kenya, South Africa, Singapore, Australia, and Denmark. Lycaenid larvae that were third instar or older were located by surveying known host plants and excavating ant nests. Larvae were collected with sterile forceps and placed in a sterile dish with no food or ants for a minimum of $5 \mathrm{~h}$ to allow their guts to evacuate. After this fasting period, larvae were killed in ethanol, rinsed in sterile PBS, and their guts were dissected using flame-sterilized dissecting tools. Dissected guts and frass were preserved in separate vials containing 97\% ethanol. For comparison, some larvae were not starved or dissected but were processed whole; these samples were rinsed in $10 \%$ bleach solution prior to DNA extraction. See Table 1 for detailed sample information.

\section{DNA Extractions and Sequencing}

Samples collected in 2014 and 2015 were processed and sequenced separately, using identical methods. DNA was extracted using the PowerSoil DNA Isolation Kit and protocols provided (MoBio Laboratories, Carlsbad, CA, USA), with the addition of a proteinase-K lysis step prior to cell disruption by bead-beating. Extracted DNA was quantified using a Qubit fluorometer (Invitrogen Inc.) for samples collected in 2014 or a NanoDrop TM1000 spectrophotometer (Thermo Scientific) for 2015 samples, and samples containing low amounts of extracted DNA were concentrated using the isolation kit's suggested protocol.

Extracted DNA was sent to Argonne National Laboratories (Lemont, IL, USA) for library preparation and sequencing of the V4 region of the $16 \mathrm{~S}$ rRNA gene. Amplicon libraries were prepared using barcoded primers $515 \mathrm{~F}$

TABLE 1 | Sample information.

\begin{tabular}{|c|c|c|c|c|c|c|}
\hline Species & Diet & Food & Country & F/G/W & Subfamily & Tribe \\
\hline Trimenia argyroplaga & Herbivorous & Unknown & South Africa & $-/ 1 /-$ & Lycaeninae & Aphnaeini \\
\hline Aloeides pallida & Carnivorous & Ant Brood & South Africa & $-/ 2 /-$ & Lycaeninae & Aphnaeini \\
\hline Aloeides thyra & Herbivorous & Zygophyllum & South Africa & $2 / 5 /-$ & Lycaeninae & Aphnaeini \\
\hline Crudaria wykehami & Carnivorous & Trophallaxis & South Africa & $-/ 11 / 2$ & Lycaeninae & Aphnaeini \\
\hline Chrysoritis thysbe & Herbivorous & Zygophyllum & South Africa & $3 / 4 /-$ & Lycaeninae & Aphnaeini \\
\hline Chrysoritis chrysanta & Herbivorous & Not recorded & South Africa & $1 / 1 /-$ & Lycaeninae & Aphnaeini \\
\hline Chrysoritis perseus & Herbivorous & Zygophyllum & South Africa & $1 / 1 /-$ & Lycaeninae & Aphnaeini \\
\hline Lycaena clarki & Herbivorous & Rumex & South Africa & $-/ 3 /-$ & Lycaeninae & Lycaenini \\
\hline Anthene usamba & Herbivorous & Vachellia & Kenya & $5 / 16 / 3$ & Lycaeninae & Polyommatini \\
\hline Anthene sp. & Herbivorous & Acacia & South Africa & $-1-/ 2$ & Lycaeninae & Polyommatini \\
\hline Chilades pandava & Herbivorous & Cycas & Singapore & $1 / 7 /-$ & Lycaeninae & Polyommatini \\
\hline Maculinea alcon & Carnivorous & Trophallaxis & Denmark & $-/ 6 / 5$ & Lycaeninae & Polyommatini \\
\hline Maculinea alcon & Herbivorous & Gentiana Flowers & Denmark & $-/ 4 / 5$ & Lycaeninae & Polyommatini \\
\hline Lachnocnema bibulus & Carnivorous & Homoptera & South Africa & $-/ 4 / 1$ & Miletinae & Lachnocnemini \\
\hline Thestor yldizae & Carnivorous & Ant Brood & South Africa & $-/ 11 /-$ & Miletinae & Lachnocnemini \\
\hline Logania marmorata & Carnivorous & Homoptera & Singapore & $-/ 7 /-$ & Miletinae & Miletini \\
\hline Miletus bigsii & Carnivorous & Homoptera & Singapore & $2 / 3 / 1$ & Miletinae & Miletini \\
\hline Feniseca tarquinius & Carnivorous & Homoptera & USA & $2 / 3 / 4$ & Miletinae & Spalgini \\
\hline Spalgis epius & Carnivorous & Homoptera & Singapore & $2 / 5 / 1$ & Miletinae & Spalgini \\
\hline Durbania amakosa & Herbivorous & Lichen & South Africa & $1 / 7 / 2$ & Poritiinae & Pentilini \\
\hline Eumaeus atala & Herbivorous & Zamia & USA & $-1-/ 6$ & Theclinae & Eumaeini \\
\hline Strymon melinus & Herbivorous & Not recorded & USA & $-/-/ 1$ & Theclinae & Eumaeini \\
\hline Eooxylides tharis & Herbivorous & Smilax & Singapore & $-/ 1 /-$ & Theclinae & Theclini \\
\hline Iolaus mimosae & Herbivorous & Mistletoe & South Africa & $-/ 1 /-$ & Theclinae & Theclini \\
\hline Iolaus trimeni & Herbivorous & Tapinanthus & South Africa & $-/ 1 /-$ & Theclinae & Theclini \\
\hline Leptomyrina sp. & Herbivorous & Cotyledon & South Africa & $-/ 1 / 1$ & Theclinae & Theclini \\
\hline Rapala iarbus & Herbivorous & Melastoma & Singapore & $-/ 1 /-$ & Theclinae & Theclini \\
\hline Surendra vivarna & Herbivorous & Albizia & Singapore & $1 / 2 /-$ & Theclinae & Theclini \\
\hline Flos sp. & Herbivorous & Not recorded & Singapore & $-/ 1 /-$ & Theclinae & Theclini \\
\hline Flos apidanus & Herbivorous & Syzygium & Singapore & $-/ 6 /-$ & Theclinae & Theclini \\
\hline Jalmenus evagoras & Herbivorous & Acacia & Australia & $-/-/ 16$ & Theclinae & Zesiini \\
\hline Jalmenus daemeli & Herbivorous & Acacia & Australia & $-1-/ 4$ & Theclinae & Zesiini \\
\hline
\end{tabular}

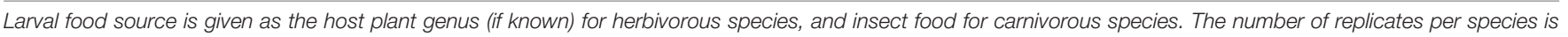
given as the number of frass (F), dissected gut (G), and whole larvae (W) samples. Tribe designations follow Eliot (1973). 
(5'-GTGYCAGCMGCCGCGGTAA - $\left.3^{\prime}\right)$ and 806R (5' GGACTACNVGGGTWTCTAAT - $3^{\prime}$ ) and previously published methods (Caporaso et al., 2012). Libraries were pooled and sequenced on an Illumina MiSeq sequencer using 150 bp pairedend sequencing technology. Sequences and associated metadata were deposited in the EMBL-EBI database ${ }^{1}$ under accession number ERP019556.

\section{Data Preprocessing}

Sequence libraries were demultiplexed using QIIME version 1.8.0 (Caporaso et al., 2010a) applying a minimum Phred quality score of 20. Because read quality was lower in reverse reads than forward reads, only high quality forward reads were used. The 2014 and 2015 sequencing libraries were concatenated and sequences were de novo clustered at $97 \%$ identity into Operational Taxonomic Units (OTUs) using UPARSE (Edgar, 2013). Chimeric sequences were removed using UCHIME (Edgar et al., 2011) and the GOLD reference database (Reddy et al., 2015). Taxonomy was assigned to clusters within QIIME with the RDP classifier (Wang et al., 2007) trained on the Greengenes database version 13_8 (DeSantis et al., 2006) with default confidence levels. Representative sequences were then aligned using PyNast (Caporaso et al., 2010b) and a phylogenetic tree was constructed using FastTree (Price et al., 2009) implemented in QIIME.

The resulting biom table, phylogenetic tree, and mapping file were imported into R (R Core Team, 2016) as a phyloseq data object using the phyloseq package (McMurdie and Holmes, 2013). Non-bacterial OTUs (e.g., Archaea and unclassified sequences) were removed, and OTU tables were rarified to 10,000 sequences per sample, retaining samples with at least 1,000 sequences.

Bacterial communities were characterized using the phyloseq package in R. Exploratory analyses demonstrated that the prevalence of chloroplast sequences varied among samples. Due to ancient homology between bacterial $16 \mathrm{~S}$ and Eukaryotic organellar $16 \mathrm{~S}$ sequences, it is common for chloroplast and mitochondrial sequences to co-amplify with bacterial sequences when using universal bacterial primers (Ghyselinck et al., 2013; Hanshew et al., 2013). These non-target sequences are typically removed prior to analysis, but because we aimed to compare the gut communities of herbivorous and carnivorous insects, we first examined the prevalence of chloroplast sequences across samples. Proportions of chloroplast to non-chloroplast sequences were calculated for each frass, dissected gut, and whole larva sample. Non-parametric Kruskal-Wallis tests (adjusted for multiple comparisons) and two-sample Wilcoxon rank sum tests were used to compare chloroplast prevalence between tissue types and diets, respectively, using the stats and pgirmess packages (Giraudoux, 2016; R Core Team, 2016). Following these statistical tests, chloroplast and mitochondria sequences were removed.

We also observed highly variable prevalence of Wolbachia sequences, with Wolbachia comprising over $95 \%$ of some samples' total libraries. Non-parametric tests were again used to compare Wolbachia prevalence between tissue types and diets.

${ }^{1}$ http://www.ebi.ac.uk/
Because Wolbachia are likely to be present intracellularly in the tissues of either the host or prey and are not known to be an important functional contributor extracellularly in the gut (Pietri et al., 2016), these sequences were removed prior to downstream analysis.

After removing these sequences, the OTU table representing gut and larva samples was re-rarefied and filtered of OTUs comprising less than $0.01 \%$ of the rarefied library within each species. Observed richness and Shannon diversity measures of herbivorous and carnivorous samples were compared using two-sample Wilcoxon rank sum tests. Weighted and unweighted UniFrac pairwise distance matrices were calculated and visualized using NMDS ordination. Family and genus level taxonomy were summarized in separate OTU tables and subjected to Linear Discriminant Analysis using the Galaxy (Afgan et al., 2016) implementation of LEfSe (Segata et al., 2011) with a minimum logarithmic LDA score of 2 and a maximum $p$-value of 0.05 .

\section{Estimated Functional Profiles}

The functional profiles of lycaenids' gut bacteria were estimated using PICRUSt (Langille et al., 2013) within the Galaxy server. The filtered, rarefied OTU table from $\mathrm{R}$ was further filtered to remove de novo OTUs and retain only OTUs with Greengene IDs. After normalizing the resulting closed reference OTU table in PICRUSt, the table was used to predict metagenomic functions in the form of KEGG Orthologs (Kanehisa and Goto, 2000), which were then collapsed into KEGG Pathways at levels 2 and 3 in the KEGG Orthology hierarchy. Both tables were tested for the presence of differentially abundant features using LEfSe.

\section{Enterobacteriaceae Tree}

Some of the most commonly observed OTUs in our dataset were identified as belonging to the Enterobacteriaceae, a bacterial family that includes many known insect symbionts. In order to identify the phylogenetic placement of these Enterobacteriaceae OTUs, a phylogenetic tree was constructed within the framework of existing GenBank stored sequences found through NCBI's MOLE-BLAST tool for clustering sequences with their database neighbors. The resulting sequences and alignment were downloaded, and models of evolution were tested with JModelTest 2.1.10 (Darriba et al., 2012). Using Bayesian Information Criterion, the TPM2 $+\mathrm{G}$ model was selected with a minus log likelihood of 1322.5509. A maximum likelihood tree was estimated using this model in PhyML 3.1 (Guindon et al., 2010).

\section{RESULTS}

Frass samples contained significantly higher proportions of chloroplast sequences than both dissected guts and whole larvae $(p<0.05$; Figure 1A), but the proportion of chloroplast sequences did not differ between samples of whole larvae that had not been starved and samples of dissected guts from larvae that had been starved, suggesting that starvation and dissection were not effective in removing chloroplasts from the gut. As 

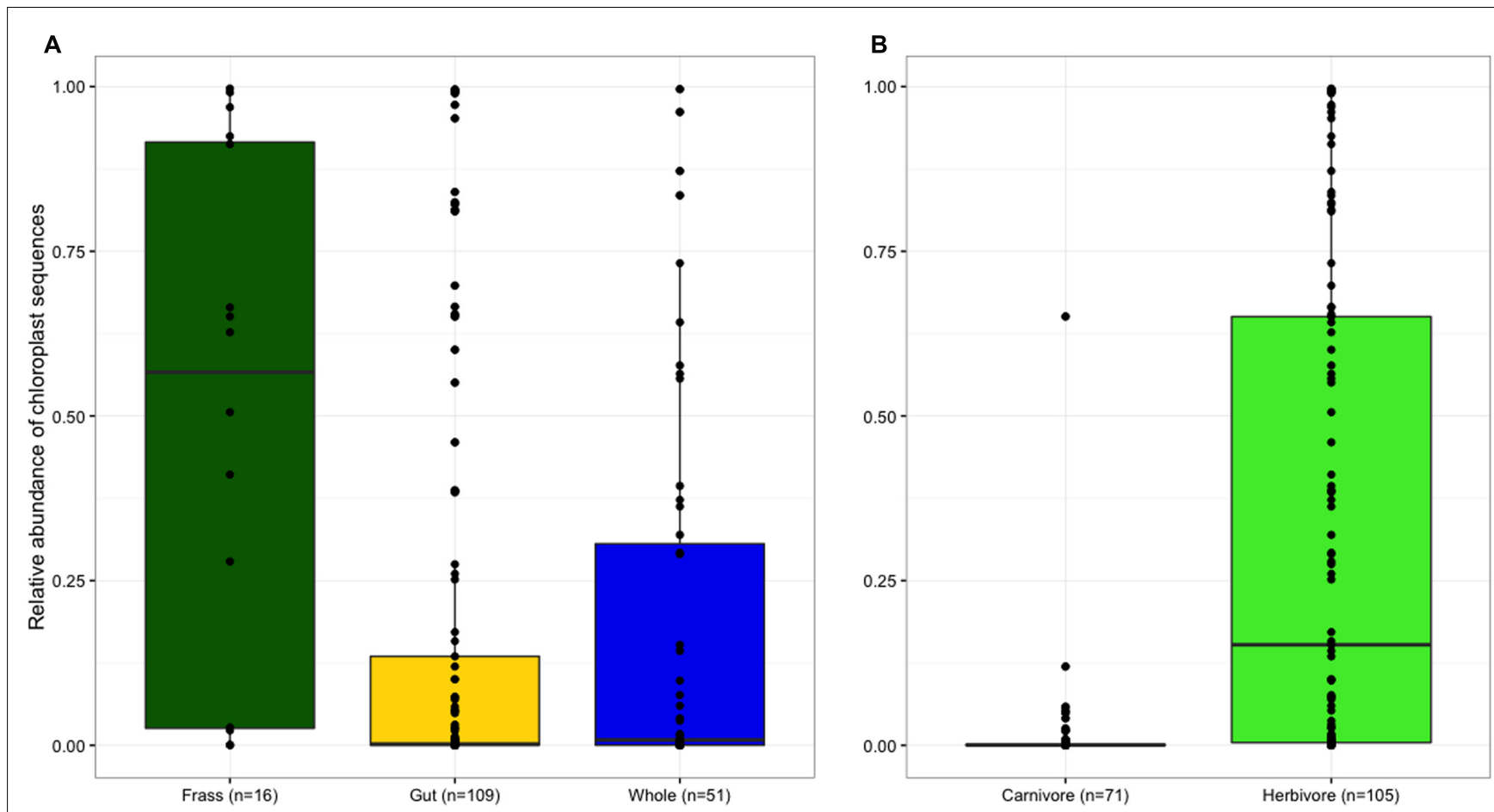

FIGURE 1 | Frass samples contained significantly higher proportions of chloroplast sequences than both dissected guts and whole larvae, but the proportion of chloroplast sequences in whole larvae and dissected guts did not significantly differ (A). Chloroplast prevalence was significantly higher in herbivorous samples than carnivorous individuals (B).

expected, chloroplast prevalence was significantly higher in herbivorous samples than carnivorous individuals $(p<0.001$, Figure 1B). Wolbachia was largely absent from frass samples but similarly abundant in both whole larvae and dissected guts (Figure 2A), indicating that Wolbachia are present in the gut tissues of lycaenid larvae and not simply in other tissues such as reproductive organs and nervous tissue. No significant difference in Wolbachia prevalence between diets was observed (Figure 2B).

After quality filtering and rarefaction, we identified 1,156 OTUs across 83 lycaenid samples. Dominant phyla included Bacteroidetes, Firmicutes, Proteobacteria, and Actinobacteria (Figure 3). Observed OTUs belong to a total of 115 bacterial families, the most abundant of which are shown in Figure 4. The 10 most abundant families across the entire dataset were Enterobacteriaceae, Alicyclobacillaceae, Staphylococcaceae, Methylobacteriaceae, Enterococcaceae, Moraxellaceae, Pseudomonadaceae, Corynebacteriaceae, Sphingomonadaceae, and Tremblayaceae. The most abundant family, Enterobacteriaceae, was observed across both herbivorous and carnivorous species (see Supplementary Image 1 for the phylogenetic placement of Enterobacteriaceae OTUs). This large bacterial family includes many known insect symbionts such as Buchnera, Tremblaya, and Serratia. Several known insect endosymbionts were detected in the guts of the lycaenids surveyed (Figure 5), particularly in entomophagous species.

Neither OTU richness nor Shannon diversity differed between herbivorous and carnivorous species. Similarly, ordination methods did not reveal any structure or clustering of lycaenid larvae according to larval diet (Figure 6A) or lycaenid tribe (Figure 6B). Conspecific samples tended to cluster together, indicating that individuals of the same species tend to have more similar bacterial communities compared to other species with similar diets or those belonging to the same tribe.

LEfSe analysis of predicted metagenomes from the PICRUSt pipeline failed to identify any predicted KEGG genes or pathways that were significantly enriched in either diet at either hierarchical level. Similarly, LEfSe analysis of bacterial taxonomy did not identify any differentially abundant OTUs at either the family or genus levels.

\section{DISCUSSION}

We characterized the gut bacterial communities of diverse lycaenid larvae using $16 \mathrm{~S}$ rRNA amplicon sequencing. We compared the bacterial abundance, richness, composition, and estimated functional profiles of carnivorous and herbivorous species to test for convergence in the microbiomes of species with similar larval diets. Despite our expectation that the gut microbial communities of herbivorous and carnivorous species would differ consistently, we observed a high degree of stochasticity in the microbiomes of lycaenid larvae, with no significant differences between herbivorous and carnivorous species in bacterial richness, diversity, or community composition. This contrasts with patterns that have been observed in vertebrates (Ley et al., 2008; Muegge et al., 2011) and in ants (Russell et al., 

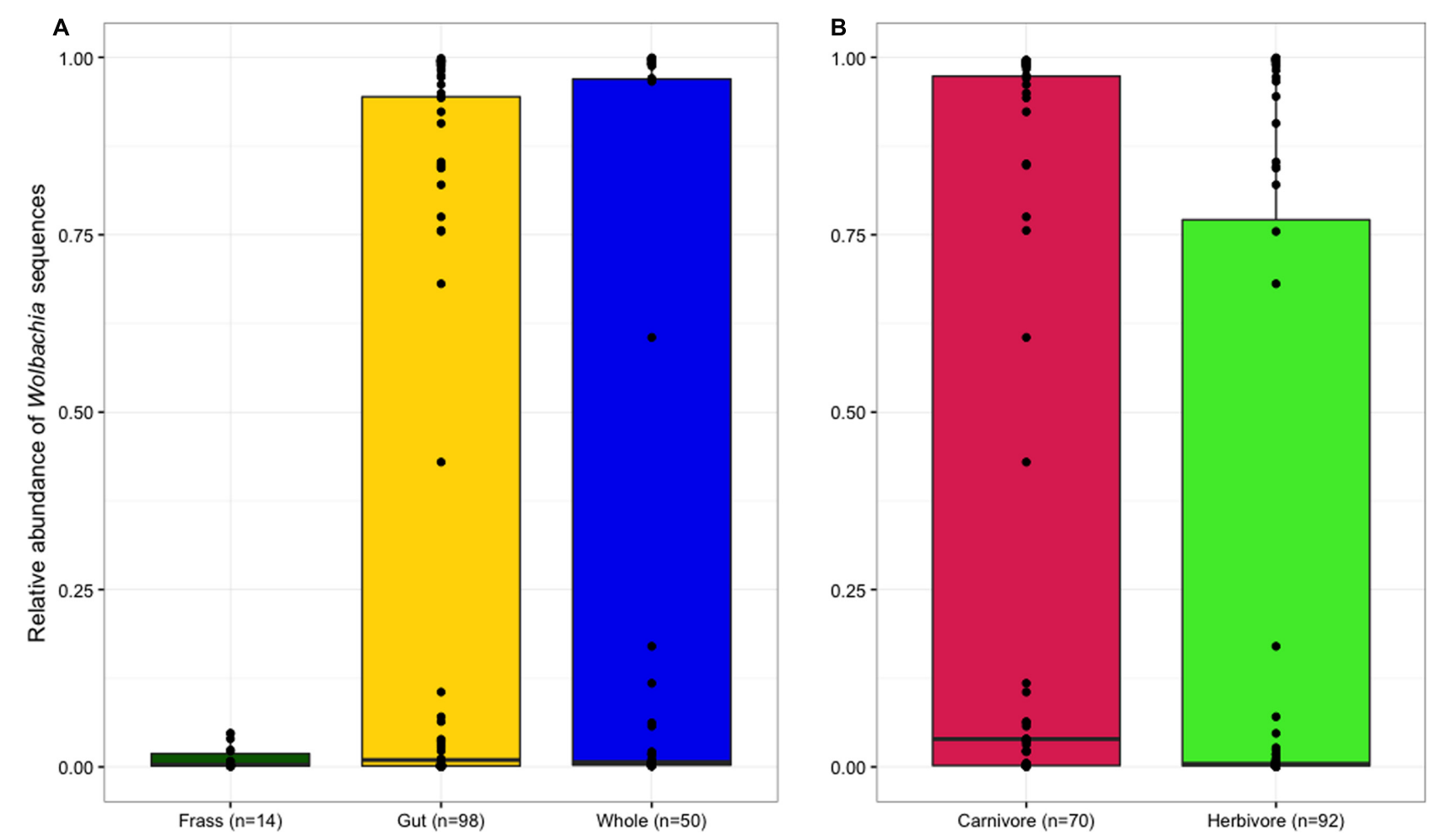

FIGURE 2 | Wolbachia sequences were mostly absent from frass samples, but were similarly abundant in dissected guts and whole larvae (A).

Wolbachia prevalence was not significantly different between larval diets (B).

2009b). Moreover, we did not observe any major and repeatable differences in bacterial composition, based on weighted and unweighted UniFrac distance metrics. While ordinations indicate that individuals of the same species tend to harbor more similar bacterial communities in their guts, considerable intraspecific variation among individuals was also observed.

The most striking differences between herbivorous and carnivorous lycaenid gut communities arise from ribosomal DNA sequences that are likely food-derived. In our raw dataset, chloroplast SSU rDNA, likely originating from ingested plant material, dominated many of the herbivorous lycaenid gut samples, but was largely absent from the carnivorous species (Figure 1B). Chloroplast sequences dominated herbivore frass to an even greater degree, indicating communities of plantdegrading microbes do not colonize the plant material during its passage through the gut. This suggests that sequence-based approaches such as chloroplast barcoding may be a fruitful means of describing the diets of lycaenid species for which larval diets are unknown. Barcoding methods have proved successful in studying the feeding ecologies of many novel taxa (Clare, 2014; De Barba et al., 2014; Gebremedhin et al., 2016), and the analysis of frass samples permits dietary investigation without destructive sampling.

Among carnivorous lycaenids, many of the abundant bacteria detected in the gut are known to be important symbionts in other insects. Often, the presence of these bacteria in the guts of lycaenid larvae could be traced to the larval food source. For example, Buchnera sequences were commonly found in the guts of Feniseca tarquinius, Miletus bigsii, and Logania marmorata, three lycaenid species that feed on aphids. The libraries of Lachnocnema bibulous larvae, which feed on ant-tended planthoppers, were nearly entirely comprised of sequences identified as Candidatus Phlomobacter, a phloemborne plant pathogen vectored by planthoppers. Other known homopteran symbionts such as Sulcia, Tremblaya, and Serratia were found in the guts of lycaenids that feed on aphids and mealybugs. While the presence of these bacteria is attributable to the entomophagous diets of these lycaenid species, it is unclear whether they could continue to confer nutritional benefits inside the lycaenid gut. Only a few studies have explored the digestion and decay rates of prey-derived bacteria in the guts of predatory insects (e.g., Paula et al., 2015), and further research is needed to examine whether these endosymbionts might continue to provision nutrients inside the larval gut.

Although we find evidence for food-derived bacteria in the guts of carnivorous lycaenid larvae, we do not observe differences in Wolbachia abundance between larval diets, suggesting that insect prey do not horizontally transmit Wolbachia to their lycaenid predators. The possibility that Wolbachia may be horizontally transmitted via feeding on infected prey has been previously suggested (Kittayapong et al., 2003; Sintupachee et al., 2006), and many Hemiptera are 

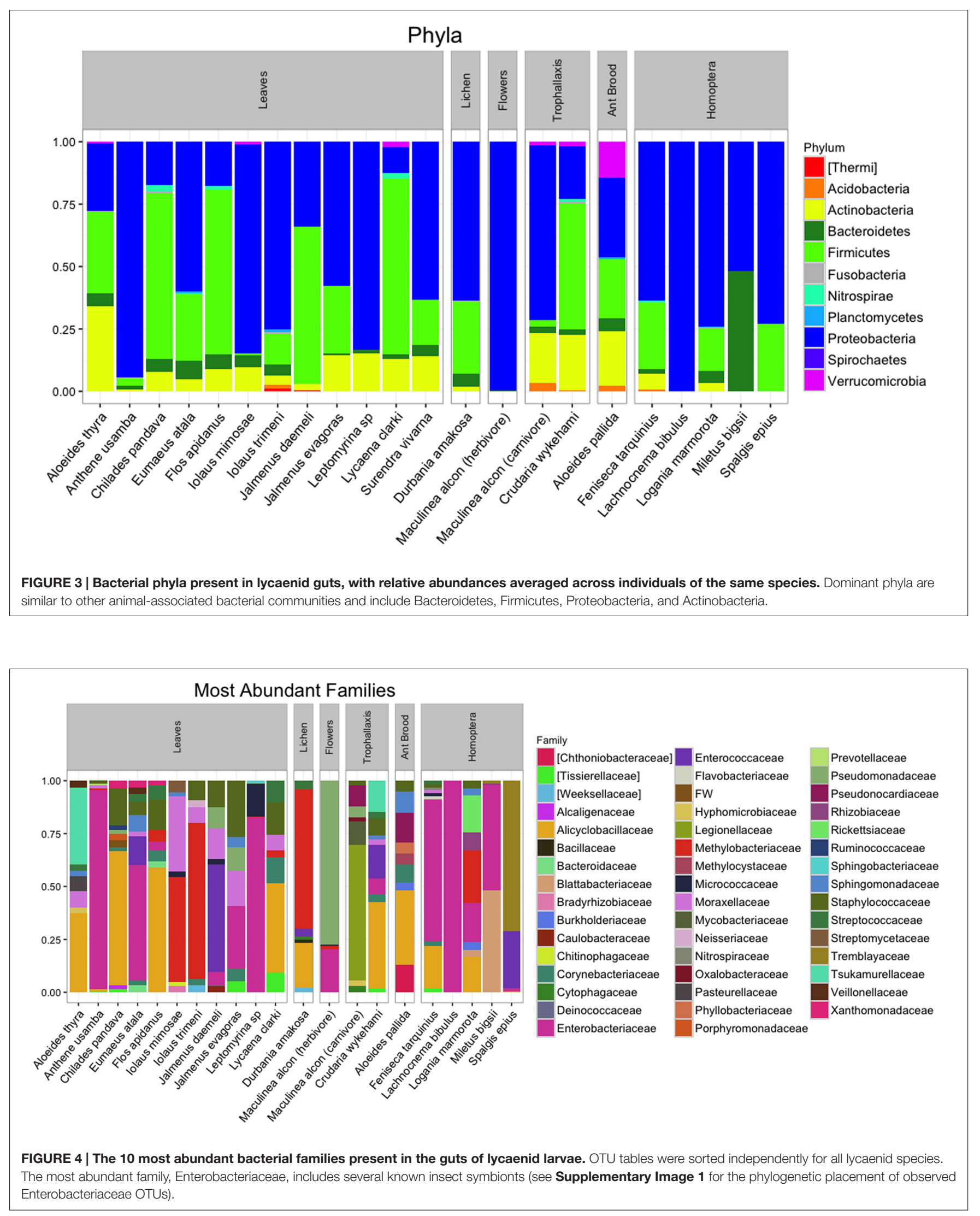


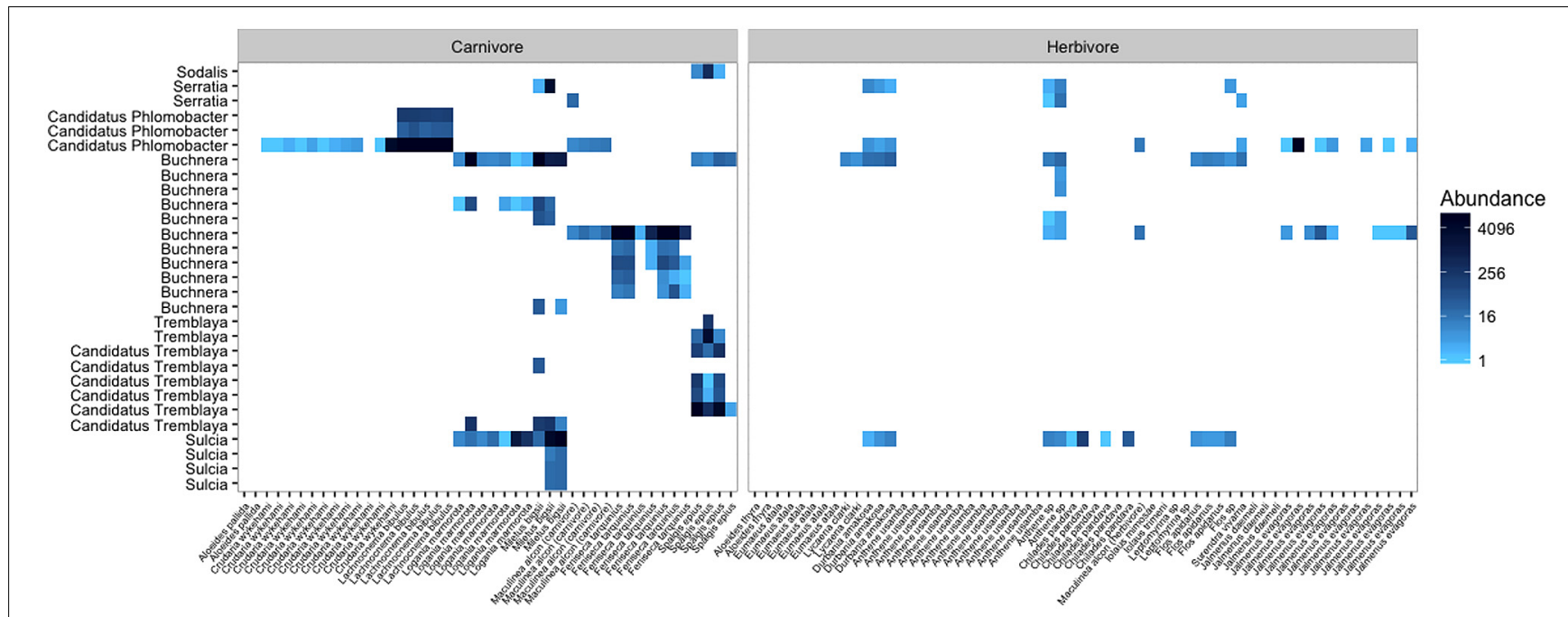

FIGURE 5 | The abundances of insect symbionts present in carnivorous and herbivorous lycaenid guts. The color scale is a log transformation with base 4, the default scale for the phyloseq package. Insect symbionts are most abundant in entomophagous lycaenid species, but are present in lower abundances in some herbivores as well. This could be attributable to sequencing errors, or it could be that facultative or accidental homopterophagy is more common than previously thought.

known to harbor Wolbachia (Augustinos et al., 2011; Hughes et al., 2011). However, horizontal transmission of Wolbachia between insects is most successful within closely related insect groups (Russell et al., 2009a), and it may be that lycaenids and their insect prey are too distantly related for such an exchange.

While our results show that known symbionts are unlikely to be directly associated with carnivorous lycaenid larvae, identifying which bacteria are likely to be food-derived in herbivorous species is not straightforward. Many of the major bacterial groups observed in this dataset are commonly isolated from aquatic and terrestrial sources, and are therefore expected to be environmentally derived in both herbivorous and carnivorous species. Alicyclobacillus, Methylobacterium, Acinetobacter, and Agrobacterium represent some of the most abundant bacterial genera in our dataset, and all are common in soil and leaf surfaces (Vorholt, 2012; Kovaleva et al., 2014; Tianli et al., 2014).

The presence of Pantoea in several herbivorous lycaenid samples is also of interest. Pantoea is a genus within the Enterobacteriaceae that has been recorded from numerous aquatic, terrestrial, and animal sources (Walterson and Stavrinides, 2015). Members of this genus are well-known plant pathogens, and it is possible that their presence in the guts of herbivorous larvae is simply due to feeding on infected plants. On the other hand, Pantoea strains have been isolated from the guts of several animals, including other insects. Although the nature of Pantoea-host associations is largely unknown, recent studies have demonstrated that Pantoea are important mutualistic symbionts in stinkbugs (Duron and Noël, 2016; Hosokawa et al., 2016). The potential for Pantoea to act as pathogenic or mutualistic gut bacteria in Lepidopteran larvae remains unexplored.
Taken together, our results suggest that lycaenids do not maintain distinctive gut communities, but are instead characterized by transient and often food-derived bacteria. Although these bacteria may not seem as important for host fitness as do obligate, vertically transmitted bacteria, it is nevertheless possible for environmentally derived OTUs to contribute to host nutrition. It may be that gut bacteria are highly conserved between lycaenid species with similar diets, but that the most influential OTUs are rare and therefore not likely to be identified using the sequencing and statistical techniques implemented here. However, while the possibility for influential but rare gut bacteria cannot be dismissed, nutritional mutualists might be expected to be reasonably common across individuals and species if they perform important functions for their hosts.

Of course, bacterial communities can differ or converge not only in taxonomic composition, but also in functional composition (Burke et al., 2011). We addressed the possibility that the gut communities of lycaenids with similar diets may be functionally convergent, even if not taxonomically similar, by predicting the functional profiles using PICRUSt. However, this method did not detect any differentially abundant functions in our dataset. The accuracy of this method is limited by the quality and availability of appropriate reference databases (Langille et al., 2013). Although lycaenids do not appear to associate with particular bacterial OTUs, they may associate with functionally similar bacteria that mediate important aspects of their diet. The community profiling methods we have used do not provide detailed information about bacterial function, and deep metagenomic sequencing will be necessary to definitively characterize and compare the functional profiles of lycaenid gut bacterial communities. 

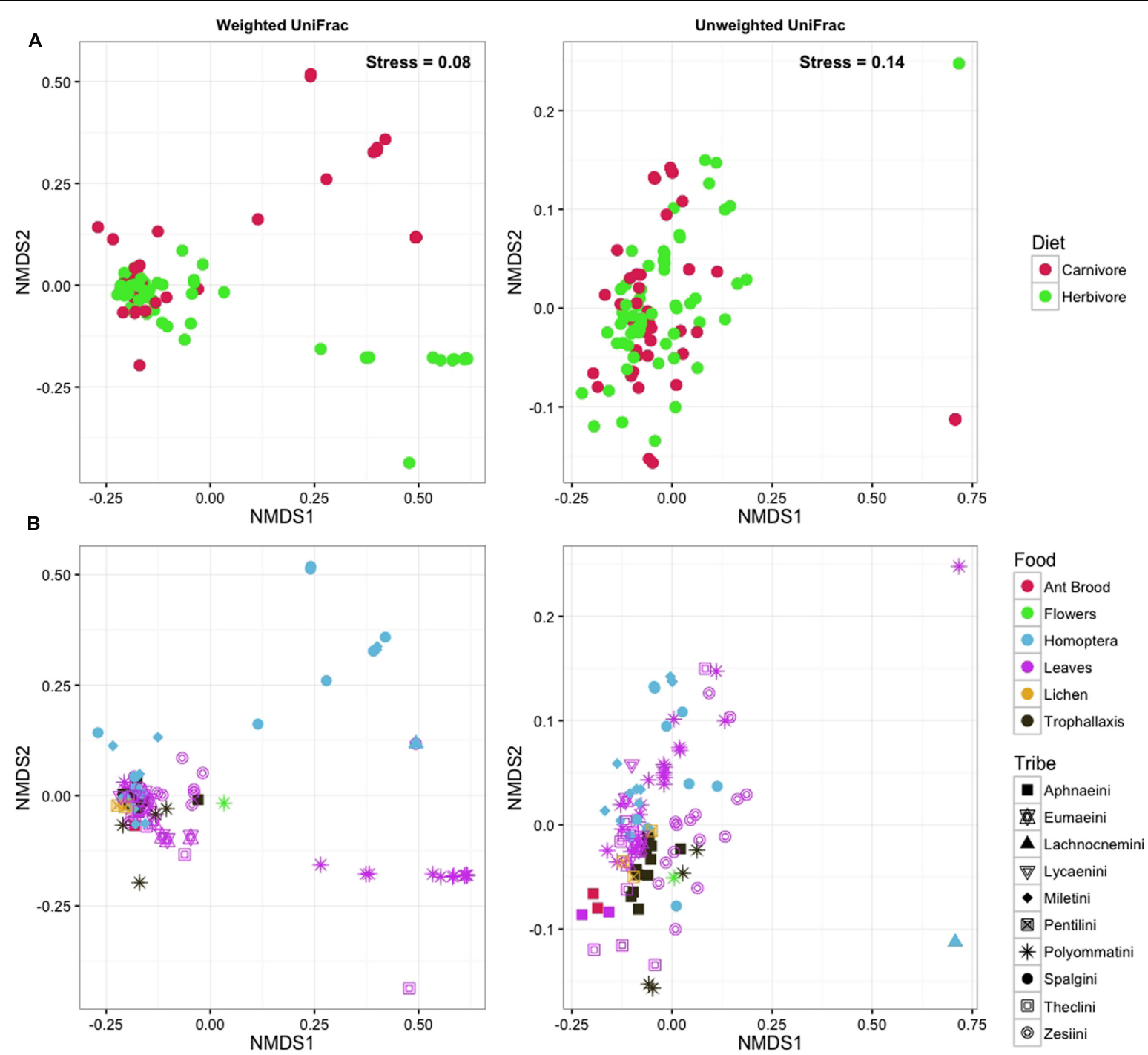

FIGURE 6 | NMDS plots with points colored according to larval diet (A) and according to lycaenid species with shapes corresponding to lycaenid tribe (B) do not demonstrate compositional similarities according to host diet or phylogeny.

While symbiotic bacteria are known to be important in many insect species, they represent only a portion of the microbial contributions to insect nutrition. Viruses, protists, and fungi could also increase the metabolic potential of their animal hosts, and it is possible that these other microorganisms mediate the exploitation of host diet in ways that have not yet been identified. Relatively few studies have explored this possibility in other Lepidoptera, although recent work has shown that the fungal communities associated with one species of lycaenid butterfly are relatively small and are likely to be environmentally derived (Harrison et al., 2016).

Despite the inordinate dietary diversity among lycaenid butterflies, their gut bacterial communities do not appear to be more selective than other Lepidoptera. Although innumerable studies have identified obligate or persistent bacterial associations in some insect species, the majority of insects harbor low diversity gut microbiomes that are highly variable among species (Colman et al., 2012). These insects do not seem to rely on the nutritional services of symbiotic gut bacteria, yet they still must cope with the challenges and deficiencies of an herbivorous lifestyle, and it is unclear how they do so.

Perhaps the most intriguing possibility is that lycaenids themselves might possess endogenous genes for encoding important digestive enzymes related to herbivory, as has been shown in some termites, beetles, flies, and crickets (Watanabe et al., 1998; Watanabe and Tokuda, 2010; Whiteman et al., 2012). In such cases, the genes in question could be ancestral within insect clades, or they could be recently acquired from microbes through horizontal gene transfer events (Hansen and Moran, 2014; Wybouw et al., 2016). Cases of horizontal gene 
transfer between microorganisms and animals are becoming increasingly well documented, including within the Lepidoptera (Husnik et al., 2013), and comparative studies indicate that horizontal gene transfer is particularly prevalent in arthropods, relative to other animals (Hotopp et al., 2007; Hotopp, 2011). Although lycaenid larvae do not appear to maintain readily identifiable associations with gut bacteria, they may have acquired key metabolic capabilities through horizontal gene transfer events during ancient bacterial associations. Subsequent losses of these functions following transitions to carnivory could also explain why reversions from carnivory back to herbivory are unknown among lycaenids.

In this study, we provide further evidence that Lepidoptera harbor taxonomically depauperate gut bacterial communities relative to other organisms, even in a clade whose species exhibit unusual trophic diversity. This is in contrast to other insect groups in which gut bacteria are known to play an important role in mediating host diet, and to vertebrates, including mammals, for which the host diet and phylogeny both contribute to bacterial associations. Although host-microbe symbioses are ubiquitous among animals, the nature of these symbioses likely depends on the exact diets, nutritional limitations, and life histories of animal hosts, and our findings demonstrate that it should not be assumed that gut bacteria influence host diet in all taxa.

\section{AUTHOR CONTRIBUTIONS}

MW and NP conceived of the project. MW and SS conducted the fieldwork and lab work; and MW, SS, and JS analyzed the data with input from MK. All Authors contributed to the preparation of the manuscript.

\section{REFERENCES}

Afgan, E., Baker, D., van den Beek, M., Blankenberg, D., Bouvier, D., Čech, M., et al. (2016). The galaxy platform for accessible, reproducible and collaborative biomedical analyses. Nucleic Acids Res. 44, W3-W10. doi: 10.1093/nar/ gkw343

Augustinos, A. A., Santos-Garcia, D., Dionyssopoulou, E., Moreira, M., Papapanagiotou, A., Scarvelakis, M., et al. (2011). Detection and characterization of Wolbachia infections in natural populations of aphids: is the hidden diversity fully unraveled? PLoS ONE 6:e28695. doi: 10.1371/journal.pone.0028695

Barbosa, P., Krischik, V. A., and Jones, C. G. (1991). Microbial Mediation of Plant-Herbivore Interactions. New York, NY: Wiley-Interscience.

Baumann, P. (2005). Biology of bacteriocyte-associated endosymbionts of plant sap- sucking insects. Annu. Rev. Microbiol. 59, 155-189.

Bayon, C., and Mathelin, J. (1980). Carbohydrate fermentation and byproduct absorption studied with labeled cellulose in Oryctes nasicornis larvae (Coleoptera, Scarabaeidae). J. Insect Physiol. 26, 833-840. doi: 10.1016/00221910(80)90100-6

Becerra, J. X., Venable, G. X., and Saeidi, V. (2015). Wolbachia-free heteropterans do not produce defensive chemicals or alarm pheromones. J. Chem. Ecol. 41, 593-601. doi: 10.1007/s10886-015-0596-4

Behar, A., Yuval, B., and Jurkevitch, E. (2005). Enterobacteria-mediated nitrogen fixation in natural populations of the fruit fly Ceratitis capitata. Mol. Ecol. 14, 2637-2643. doi: 10.1111/j.1365-294X.2005.02615.x

\section{FUNDING}

MW was supported by a National Science Foundation Postdoctoral Research Fellowship in Biology (1309425); SS and JS were supported by NSF Graduate Research Fellowships; the research was funded by grants to MW from the British Ecological Society (6007210), the Putnam Expeditionary Fund of the Museum of Comparative Zoology, the Wildlife Reserves Singapore Conservation Fund, and the Explorer's Club; the Max Planck Society (to MK), and an FQEB grant from the Templeton Foundation and NSF SES 075048 to NP.

\section{ACKNOWLEDGMENTS}

Aileen Berasategui, Hassan Salem, and Leonora Bittleston provided thoughtful feedback on the research. We are grateful to Alan Heath, Andre Coetzer, and other members of the Lepidopterists Society of South Africa; Dino Martins, Anne Powys, Gilfred Powys and the staff at Suyian in Laikipia, Kenya, Horace Tan and the Butterfly Circle; and Ada Kaliszewska, Elizabeth Long, Sebastian Pohl, and David Nash for invaluable assistance with fieldwork and collecting.

\section{SUPPLEMENTARY MATERIAL}

The Supplementary Material for this article can be found online at: http://journal.frontiersin.org/article/10.3389/fmicb. 2016.01920/full\#supplementary-material

IMAGE 1| The presence of Enterobacteriaceae OTUs found in herbivorous and carnivorous larvae are mapped onto the phylogenetic tree of Enterobacteriaceae, with pie charts representing the percent of lycaenid species within each diet category for which the OTU was present.

Belda, E., Pedrola, L., Peretó, J., Martínez-Blanch, J. F., Montagud, A., Navarro, E., et al. (2011). Microbial diversity in the midguts of field and lab-reared populations of the european corn borer Ostrinia nubilalis. PLoS ONE 6:e21751. doi: 10.1371/journal.pone.0021751

Berenbaum, M. R. (1988). "Allelochemicals in insect-microbe-plant interactions; agents provocateurs in the coevolutionary arms race," in Novel Aspects of InsectPlant Interactions, eds P. Barbosa and D. K. Letourneau (New York, NY: Wiley-Interscience), 97-123.

Boone, C. K., Keefover-Ring, K., Mapes, A. C., Adams, A. S., Bohlmann, J., and Raffa, K. F. (2013). Bacteria associated with a tree-killing insect reduce concentrations of plant defense compounds. J. Chem. Ecol. 39, 1003-1006. doi: 10.1007/s10886-013-0313-0

Brinkmann, N., Martens, R., and Tebbe, C. C. (2008). Origin and diversity of metabolically active gut bacteria from laboratory-bred larvae of Manduca sexta (Sphingidae, Lepidoptera, Insecta). Appl. Environ. Microbiol. 74, 7189-7196. doi: 10.1128/AEM.01464-08

Broderick, N. A., Raffa, K. F., Goodman, R. M., and Handelsman, J. (2004). Census of the bacterial community of the gypsy moth larval midgut by using culturing and culture-independent methods. Appl. Environ. Microbiol. 70, 293-300. doi: 10.1128/AEM.70.1.293-300.2004

Brownlie, J. C., Cass, B. N., Riegler, M., Witsenburg, J. J., Iturbe-Ormaetxe, I., McGraw, E. A., et al. (2009). Evidence for metabolic provisioning by a common invertebrate endosymbiont, Wolbachia pipientis, during periods of nutritional stress. PLoS Pathog. 5:e1000368. doi: 10.1371/journal.ppat. 1000368 
Brune, A. (2014). Symbiotic digestion of lignocellulose in termite guts. Nat. Rev. Microbiol. 12, 168-180. doi: 10.1038/nrmicro3182

Buchner, P. (1965). Endosymbiosis of Animals with Plant Microorganisms. New York, NY: John Wiley.

Burke, C., Steinberg, P., Rusch, D., Kjelleberg, S., and Thomas, T. (2011). Bacterial community assembly based on functional genes rather than species. Proc. Natl. Acad. Sci. U.S.A. 108, 14288-14293. doi: 10.1073/pnas.1101591108

Campbell, B. C., Bragg, T. S., and Turner, C. E. (1992). Phylogeny of symbiotic bacteria of four weevil species (Coleoptera: Curculionidae) based on analysis of 16 S ribosomal DNA. Insect Biochem. Mol. Biol. 22, 415-421. doi: 10.1016/09651748(92)90136-3

Caporaso, J. G., Bittinger, K., Bushman, F. D., DeSantis, T. Z., Andersen, G. L., and Knight, R. (2010a). PyNAST: a flexible tool for aligning sequences to a template alignment. Bioinformatics 26, 266-267. doi: 10.1093/bioinformatics/btp636

Caporaso, J. G., Kuczynski, J., Stombaugh, J., Bittinger, K., Bushman, F. D., Costello, E. K., et al. (2010b). QIIME allows analysis of high-throughput community sequencing data. Nat. Methods 7, 335-336. doi: 10.1038/nmeth. f.303

Caporaso, J. G., Lauber, C. L., Walters, W. A., Berg-Lyons, D., Huntley, J., Fierer, N., et al. (2012). Ultra-high-throughput microbial community analysis on the Illumina HiSeq and MiSeq platforms. ISME J. 6, 1621-1624. doi: 10.1038/ismej. 2012.8

Ceja-Navarro, J. A., Vega, F. E., Karaoz, U., Hao, Z., Jenkins, S., Lim, H. C., et al. (2015). Gut microbiota mediate caffeine detoxification in the primary insect pest of coffee. Nat. Commun. 6:7618. doi: 10.1038/ncomms8618

Clare, E. L. (2014). Molecular detection of trophic interactions: emerging trends, distinct advantages, significant considerations and conservation applications. Evol. Appl. 7, 1144-1157. doi: 10.1111/eva.12225

Colman, D. R., Toolson, E. C., and Takacs-Vesbach, C. D. (2012). Do diet and taxonomy influence insect gut bacterial communities? Mol. Ecol. 21, 5124-5137. doi: 10.1111/j.1365-294X.2012.05752.x

Darriba, D., Taboada, G. L., Doallo, R., and Posada, D. (2012). jModelTest 2: more models, new heuristics and parallel computing. Nat. Methods 9, 772-772. doi: 10.1038/nmeth.2109

De Barba, M., Miquel, C., Boyer, F., Mercier, C., Rioux, D., Coissac, E., et al. (2014). DNA metabarcoding multiplexing and validation of data accuracy for diet assessment: application to omnivorous diet. Mol. Ecol. Resour. 14, 306-323. doi: 10.1111/1755-0998.12188

DeSantis, T. Z. P., Hugenholtz Larsen, N., Rojas, M., Brodie, E. L., Keller, K., Huber, T., et al. (2006). Greengenes, a chimera-checked 16S rRNA gene database and workbench compatible with ARB. Appl. Environ. Microbiol. 72, 5069-5072. doi: 10.1128/AEM.03006-05

Douglas, A. E. (1998). Nutritional interactions in insect-microbial symbioses: aphids and their symbiotic bacteria Buchnera. Annu. Rev. Entomol. 43, 17-37.

Duron, O., and Noël, V. (2016). A wide diversity of Pantoea lineages are engaged in mutualistic symbiosis and cospeciation processes with stinkbugs. Environ. Microbiol. Rep. doi: 10.1111/1758-2229.12432 [Epub ahead of print].

Edgar, R. C. (2013). UPARSE: highly accurate OTU sequences from microbial amplicon reads. Nat. Methods 10, 996-998. doi: 10.1038/nmeth.2604

Edgar, R. C., Haas, B. J., Clemente, J. C., Quince, C., and Knight, R. (2011). UCHIME improves sensitivity and speed of chimera detection. Bioinformatics 27, 2194-2200. doi: 10.1093/bioinformatics/btr381

Eliot, J. N. (1973). The higher classification of the Lycaenidae (Lepidoptera): a tentative arrangement. Bull. Br. Mus. Nat. Hist. (Entomology) 28, 371-505.

Engel, P., Martinson, V. G., and Moran, N. A. (2012). Functional diversity within the simple gut microbiota of the honey bee. Proc. Natl. Acad. Sci. U.S.A. 109, 11002-11007. doi: 10.1073/pnas.1202970109

Feldhaar, H. (2011). Bacterial symbionts as mediators of ecologically important traits of insect hosts. Ecol. Entomol. 36, 533-543. doi: 10.1111/j.1365-2311.2011. 01318.x

Felton, G. W., and Tumlinson, J. H. (2008). Plant-insect dialogs: complex interactions at the plant-insect interface. Curr. Opin. Plant Biol 11, 457-463. doi: 10.1016/j.pbi.2008.07.001

Fiedler, K. (1991). Systematic, evolutionary, and ecological implications of myrmecophily within the Lycaenidae (Insecta: Lepidoptera: Papilionoidea). Bonner Zool. Monogr. 31, 1-210.

Gebremedhin, B., Flagstad, Ø., Bekele, A., Chala, D., Bakkestuen, V., Boessenkool, S., et al. (2016). DNA metabarcoding reveals diet overlap between the endangered walia ibex and domestic goats-implications for conservation. PLoS ONE 11:e0159133. doi: 10.1371/journal.pone. 0159133

Ghyselinck, J., Pfeiffer, S., Heylen, K., Sessitsch, A., and De Vos, P. (2013). The effect of primer choice and short read sequences on the outcome of 16S rRNA gene based diversity studies. PLoS ONE 8:e71360. doi: 10.1371/journal.pone.0071360

Giraudoux, P. (2016). pgirmess: Data Analysis in Ecology. R Package Version 1.6.4. Available at: https://CRAN.R-project.org/package=pgirmess.

Guindon, S., Dufayard, J., Lefort, V., Anisimova, M., Hordijk, W., and Gascuel, O. (2010). New algorithms and methods to estimate maximum-likelihood phylogenies: assessing the performance of PhyML 3.0. Syst. Biol. 59, 307-321. doi: 10.1093 /sysbio/syq010

Hamilton, P. T., and Perlman, S. J. (2013). Host defense via symbiosis in Drosophila. PLoS Pathog. 9:e1003808. doi: 10.1371/journal.ppat.1003808

Hammer, T. J., and Bowers, M. D. (2015). Gut microbes may facilitate insect herbivory of chemically defended plants. Oecologia 179, 1-14. doi: 10.1007/ s00442-015-3327-1

Hammer, T. J., McMillan, W. O., and Fierer, N. (2014). Metamorphosis of a butterfly-associated bacterial community. PLoS ONE 9:e86995. doi: 10.1371/ journal.pone.0086995

Hansen, A. K., and Moran, N. A. (2014). The impact of microbial symbionts on host plant utilization by herbivorous insects. Mol. Ecol. 23, 1473-1496. doi: $10.1111 /$ mec. 12421

Hanshew, A. S., Mason, C. J., Raffa, K. F., and Currie, C. R. (2013). Minimization of chloroplast contamination in $16 \mathrm{~S}$ rRNA gene pyrosequencing of insect herbivore bacterial communities. J. Microbiol. Methods 95, 149-155. doi: 10. 1016/j.mimet.2013.08.007

Harrison, J. G., Urruty, D. M., and Forister, M. L. (2016). An exploration of the fungal assemblage in each life history stage of the butterfly, Lycaeides melissa (Lycaenidae), as well as its host plant Astragalus canadensis (Fabaceae). Fungal Ecol. 22, 10-16. doi: 10.1016/j.funeco.2016.02.001

Hedges, L. M., Brownlie, J. C., O’Neill, S. L., and Johnson, K. N. (2008). Wolbachia and virus protection in insects. Science 322, 702-702. doi: 10.1126/science. 1162418

Hiroki, M., Kato, Y., Kamito, T., and Miura, K. (2002). Feminization of genetic males by a symbiotic bacterium in a butterfly, Eurema hecabe (Lepidoptera: Pieridae). Naturwissenschaften 89, 167-170. doi: 10.1007/s00114-002-0303-5

Hongoh, Y. (2014). Diversity and genomes of uncultured microbial symbionts in the termite gut. Biosci. Biotechnol. Biochem. 74, 1145-1151. doi: 10.1271/bbb. 100094

Hosokawa, T., Ishii, Y., Nikoh, N., Fujie, M., Satoh, N., and Fukatsu, T. (2016). Obligate bacterial mutualists evolving from environmental bacteria in natural insect populations. Nat. Microbiol. 1:15011. doi: 10.1038/nmicrobiol.2015.11

Hosokawa, T., Koga, R., Kikuchi, Y., Meng, X. Y., and Fukatsu, T. (2010). Wolbachia as a bacteriocyte-associated nutritional mutualist. Proc. Natl. Acad. Sci. U.S.A. 107, 769-774. doi: 10.1073/pnas.0911476107

Hotopp, J. C. D. (2011). Horizontal gene transfer between bacteria and animals. Trends Genet. 27, 157-163. doi: 10.1016/j.tig.2011.01.005

Hotopp, J. C. D., Clark, M. E., Oliveira, D. C. S. G., Foster, J. M., Fischer, P., Muñoz Torres, M. C., et al. (2007). Widespread lateral gene transfer from intracellular bacteria to multicellular eukaryotes. Science 317, 1753-1756. doi: $10.1126 /$ science. 1142490

Hughes, G. L., Allsopp, P. G., Brumbley, S. M., Woolfit, M., McGraw, E. A., and O'Neill, S. L. (2011). Variable infection frequency and high diversity of multiple strains of Wolbachia pipientis in Perkinsiella planthoppers. Appl. Environ. Microbiol. 77, 2165-2168. doi: 10.1128/AEM.02878-10

Hurst, G. D., Jiggins, F. M., von der Schulenburg, J. H. G., Bertrand, D., West, S. A., Goriacheva, I. I., et al. (1999). Male-killing Wolbachia in two species of insect. Proc.Biol. Sci. 266, 735-740. doi: 10.1098/rspb.1999.0698

Husnik, F., Nikoh, N., Koga, R., Ross, L., Duncan, R. P., Fujie, M., et al. (2013). Horizontal gene transfer from diverse bacteria to an insect genome enables a tripartite nested mealybug symbiosis. Cell 153, 1567-1578. doi: 10.1016/j.cell. 2013.05.040

Janson, E. M., Stireman, J. O., Singer, M. S., and Abbot, P. (2008). Phytophagous insect-microbe mutualisms and adaptive evolutionary diversification. Evolution 62, 997-1012. doi: 10.1111/j.1558-5646.2008.00348.x

Jiggins, F. M., Hurst, G. D. D., Jiggins, C. D., v d Shulenburg, J. H., and Majerus, M. E. (2000). The butterfly Danaus chrysippus is infected by a 
male-killing Spiroplasma bacterium. Parasitology 120, 439-446. doi: 10.1017/ S0031182099005867

Kaltenpoth, M., Göttler, W., Herzner, G., and Strohm, E. (2005). Symbiotic bacteria protect wasp larvae from fungal infestation. Curr. Biol. 15, 475-479. doi: 10. 1016/j.cub.2005.04.046

Kanehisa, M., and Goto, S. (2000). KEGG: kyoto encyclopedia of genes and genomes. Nucleic Acids Res. 28, 27-30. doi: 10.1093/nar/28.1.27

Kittayapong, P., Jamnongluk, W., Thipaksorn, A., Milne, J. R., and Sindhusake, C. (2003). Wolbachia infection complexity among insects in the tropical rice-field community. Mol. Ecol. 12, 1049-1060. doi: 10.1046/j.1365-294X.2003.01793.x

Kovaleva, J., Degener, J. E., and van der Mei, H. C. (2014). Methylobacterium and its role in health care-associated infection. J. Clin. Microbiol. 52, 1317-1321. doi: 10.1128/JCM.03561-13

Landry, M., Comeau, A. M., Derome, N., Cusson, M., and Levesque, R. C. (2015). Composition of the spruce budworm (Choristoneura fumiferana) midgut microbiota as affected by rearing conditions. PLoS ONE 10:e0144077. doi: 10 . 1371/journal.pone.0144077

Langille, M. G. I., Zaneveld, J., Caporaso, J. G., McDonald, D., Knights, D., Reyes, J. A., et al. (2013). Predictive functional profiling of microbial communities using 16S rRNA marker gene sequences. Nat. Biotechnol. 31, 814-821. doi: $10.1038 /$ nbt. 2676

Lapierre, P., and Gogarten, J. P. (2009). Estimating the size of the bacterial pan-genome. Trends Genet. 25, 107-110. doi: 10.1016/j.tig.2008.12.004

Ley, R. E., Hamady, M., Lozupone, C., Turnbaugh, P. J., Ramey, R. R., Bircher, J. S., et al. (2008). Evolution of mammals and their gut microbes. Science 320, 1647-1651. doi: 10.1126/science. 1155725

Martinson, V. G., Danforth, B. N., Minckley, R. L., Rueppell, O., Tingek, S., and Moran, N. A. (2011). A simple and distinctive microbiota associated with honey bees and bumble bees. Mol. Ecol. 20, 619-628. doi: 10.1111/j.1365-294X.2010. 04959.x

McCutcheon, J. P., and von Dohlen, C. D. (2011). An interdependent metabolic patchwork in the nested symbiosis of mealybugs. Curr. Biol. 21, 1366-1372. doi: 10.1016/j.cub.2011.06.051

McMurdie, P. J., and Holmes, S. (2013). phyloseq: an R package for reproducible interactive analysis and graphics of microbiome census data. PLOS ONE 8:e61217. doi: 10.1371/journal.pone.0061217

Muegge, B. D., Kuczynski, J., Knights, D., Clemente, J. C., González, A., Fontana, L., et al. (2011). Diet drives convergence in gut microbiome functions across mammalian phylogeny and within humans. Science 332, 970-974. doi: 10.1126/ science.1198719

Nikoh, N., Hosokawa, T., Moriyama, M., Oshima, K., Hattori, M., and Fukatsu, T. (2014). Evolutionary origin of insect-Wolbachia nutritional mutualism. Proc. Natl. Acad. Sci. U.S.A. 111, 10257-10262. doi: 10.1073/pnas.1409284111

Paula, D. P., Linard, B., Andow, D. A., Sujii, E. R., Pires, C. S. S., and Vogler, A. P. (2015). Detection and decay rates of prey and prey symbionts in the gut of a predator through metagenomics. Mol. Ecol. Resour. 15, 880-892. doi: 10.1111/1755-0998.12364

Pierce, N. E. (1995). Predatory and parasitic Lepidoptera: carnivores living on plants. J. Lepid. Soc. 49, 412-453.

Pierce, N. E., Braby, M. F., Heath, A., Lohman, D. J., Mathew, J., Rand, D. B., et al. (2002). The ecology and evolution of ant association in the Lycaenidae (Lepidoptera). Annu. Rev. Entomol. 47, 733-771. doi: 10.1146/annurev.ento.47. 091201.145257

Pietri, J. E., DeBruhl, H., and Sullivan, W. (2016). The rich somatic life of Wolbachia. MicrobiologyOpen 00, 1-14. doi: 10.1002/mbo3.390

Potrikus, C. J., and Breznak, J. A. (1981). Gut bacteria recycle uric acid nitrogen in termites-a strategy for nutrient conservation. Proc. Natl. Acad. Sci. U.S.A. 78, 4601-4605. doi: 10.1073/pnas.78.7.4601

Price, M. N., Dehal, P. S., and Arkin, A. P. (2009). FastTree: computing large minimum evolution trees with profiles instead of a distance matrix. Mol. Biol. Evol. 26, 1641-1650. doi: 10.1093/molbev/msp077

Priya, N. G., Ojha, A., Kajla, M. K., Raj, A., and Rajagopal, R. (2012). Host plant induced variation in gut bacteria of Helicoverpa armigera. PLOS ONE 7:e30768. doi: 10.1371/journal.pone.0030768

R Core Team (2016). R: A Language and Environment for Statistical Computing. Vienna: R Foundation for Statistical Computing.

Reddy, T. B. K., Thomas, A. D., Stamatis, D., Bertsch, J., Isbandi, M., Jansson, J., et al. (2015). The Genomes OnLine Database (GOLD) v.5: a metadata management system based on a four level (meta)genome project classification. Nucleic Acids Res. 43, D1099-D1106. doi: 10.1093/nar/gku950

Robinson, C. J., Schloss, P., Ramos, Y., Raffa, K., and Handelsman, J. (2010). Robustness of the bacterial community in the cabbage white butterfly larval midgut. Microb. Ecol. 59, 199-211. doi: 10.1007/s00248-009-9595-8

Russell, J. A., Funaro, C. F., Giraldo, Y. M., Goldman-Huertas, B., Suh, D., Kronauer, D. J. C., et al. (2012). A veritable menagerie of heritable bacteria from ants, butterflies, and beyond: broad molecular surveys and a systematic review. PLoS ONE 7:e51027. doi: 10.1371/journal.pone.0051027

Russell, J. A., Goldman-Huertas, B., Moreau, C. S., Baldo, L., Stahlhut, J. K., Werren, J. H., et al. (2009a). Specialization and geographic isolation among Wolbachia symbionts from ants and lycaenid butterflies. Evolution 63, 624-640. doi: 10.1111/j.1558-5646.2008.00579.x

Russell, J. A., Moreau, C. S., Goldman-Huertas, B., Fujiwara, M., Lohman, D. J., and Pierce, N. E. (2009b). Bacterial gut symbionts are tightly linked with the evolution of herbivory in ants. Proc. Natl. Acad. Sci. U.S.A. 106, 21236-21241. doi: 10.1073/pnas.0907926106

Salem, H., Bauer, E., Strauss, A. S., Vogel, H., Marz, M., and Kaltenpoth, M. (2014). Vitamin supplementation by gut symbionts ensures metabolic homeostasis in an insect host. Proc. Biol. Sci. 281, 20141838. doi: 10.1098/rspb.2014.1838

Salem, H., Kreutzer, E., Sudakaran, S., and Kaltenpoth, M. (2012). Actinobacteria as essential symbionts in firebugs and cotton stainers (Hemiptera, Pyrrhocoridae). Environ. Microbiol. 15, 1956-1968. doi: 10.1111/1462-2920.12001

Sanders, J. G., Powell, S., Kronauer, D. J. C., Vasconcelos, H. L., Frederickson, M. E., and Pierce, N. E. (2014). Stability and phylogenetic correlation in gut microbiota: lessons from ants and apes. Mol. Ecol. 23, 1268-1283. doi: 10.1111/ mec. 12611

Scott, J. J., Oh, D. C., Yuceer, M. C., Klepzig, K. D., Clardy, J., and Currie, C. R. (2008). Bacterial protection of beetle-fungus mutualism. Science 322, 63. doi: $10.1126 /$ science. 1160423

Segata, N., Izard, J., Waldron, L., Gevers, D., Miropolsky, L., Garrett, W. S., et al. (2011). Metagenomic biomarker discovery and explanation. Genome Biol. 12, R60. doi: 10.1186/gb-2011-12-6-r60

Shin, S. C., Kim, S.-H., You, H., Kim, B., Kim, A. C., Lee, K.-A., et al. (2011). Drosophila microbiome modulates host developmental and metabolic homeostasis via insulin signaling. Science 334, 670-674. doi: 10.1126/science. 1212782

Sintupachee, S., Milne, J. R., Poonchaisri, S., Baimai, V., and Kittayapong, P. (2006). Closely related Wolbachia strains within the pumpkin arthropod community and the potential for horizontal transmission via the plant. Mol. Ecol. 51, 294-301.

Staudacher, H., Kaltenpoth, M., Menken, S. B. J., and Heckel, D. G. (2016). Variability of bacterial communities in the moth Heliothis virescens indicates transient association with the host. PLOS ONE 11:e0154514. doi: 10.1371/ journal.pone.0154514

Strong, D. R., Lawton, J. H., and Southwood, T. R. E. (1984). Insects on Plants: Community Patterns and Mechanisms. Cambridge, MA: Harvard University Press.

Sudakaran, S., Retz, F., Kikuchi, Y., Kost, C., and Kaltenpoth, M. (2015). Evolutionary transition in symbiotic syndromes enabled diversification of phytophagous insects on an imbalanced diet. ISME J. 9, 2587-2604. doi: 10. 1038/ismej.2015.75

Tang, X., Freitak, D., Vogel, H., Ping, L., Shao, Y., Cordero, E. A., et al. (2012). Complexity and variability of gut commensal microbiota in polyphagous lepidopteran larvae. PLoS ONE 7:e36978. doi: 10.1371/journal.pone.0036978

Tianli, Y., Jiangbo, Z., and Yahong, Y. (2014). Spoilage by Alicyclobacillus bacteria in juice and beverage products: chemical, physical, and combined control methods. Compr. Rev. Food Sci. F. 13, 771-797. doi: 10.1111/1541-4337.12093

Tsuchida, T., Koga, R., and Fukatsu, T. (2004). Host plant specialization governed by facultative symbiont. Science 303, 1989-1989. doi: 10.1126/science.1094611

Vazques-Arista, M., Smith, R. H., Oldade-Portugal, V., Hinojosa, R. E., Hernandez, R., and Blanco, A. B. (1997). Cellulolytic bacteria in the digestive system of Prostephanus truncates (Coleoptera: Bostrichidae). J. Econ. Bot. 90, $1371-1376$.

Vorholt, J. A. (2012). Microbial life in the phyllosphere. Nat. Rev. Microbiol. 10, 828-840. doi: 10.1038/nrmicro2910

Walterson, A. M., and Stavrinides, J. (2015). Pantoea: insights into a highly versatile and diverse genus within the Enterobacteriaceae. 
FEMS Microbiol. Rev. 39, 968-984. doi: 10.1093/femsre/ fuv027

Wang, J., Weiss, B. L., and Aksoy, S. (2013). Tsetse fly microbiota: form and function. Front. Cell. Infect. Microbiol. 3:69. doi: 10.3389/fcimb.2013.00069

Wang, Q., Garrity, G. M., Tiedje, J. M., and Cole, J. R. (2007). Naive Bayesian classifier for rapid assignment of rRNA sequences into the new bacterial taxonomy. Appl. Environ. Microbiol. 73, 5261-5267. doi: 10.1128/AEM. 00062-07

Watanabe, H., Noda, H., Tokuda, G., and Lo, N. (1998). A cellulase gene of termite origin. Nature 394, 330-331. doi: 10.1038/28527

Watanabe, H., and Tokuda, G. (2010). Cellulolytic systems in insects. Annu. Rev. Entomol. 55, 609-632. doi: 10.1146/annurev-ento-112408-085319

Whiteman, N. K., Gloss, A. D., Sackton, T. B., Groen, S. C., Humphrey, P. T., Lapoint, R. T., et al. (2012). Genes involved in the evolution of herbivory by a leaf-mining, Drosophilid fly. Genome Biol. Evol. 4, 900-916. doi: 10.1093/gbe/ evs 063
Wybouw, N., Pauchet, Y., Heckel, D. G., and Van Leeuwen, T. (2016). Horizontal gene transfer contributes to the evolution of arthropod herbivory. Genome Biol. Evol. 8, 1785-1801. doi: 10.1093/gbe/ evw119

Conflict of Interest Statement: The authors declare that the research was conducted in the absence of any commercial or financial relationships that could be construed as a potential conflict of interest.

Copyright $\odot 2016$ Whitaker, Salzman, Sanders, Kaltenpoth and Pierce. This is an open-access article distributed under the terms of the Creative Commons Attribution License (CC BY). The use, distribution or reproduction in other forums is permitted, provided the original author(s) or licensor are credited and that the original publication in this journal is cited, in accordance with accepted academic practice. No use, distribution or reproduction is permitted which does not comply with these terms. 